\title{
Borradiognidinges aquí
}

\section{Recensiones}

FERNÁNDEZ DE GATTA SÁNCHEZ, Dionisio. Fracking y gas no convencional. Régimen jurídico. Tirant Lo Blanch, Valencia, 2017, 346 páginas.

I.- El profesor Dionisio Fernández de Gatta Sánchez, con la colaboración de Paula Fernández de Gatta Pérez, nos pone al día en la materia de la exploración y explotación del gas no convencional, en particular mediante la fracturación hidráulica, mediante esta valiosa monografía con la que contribuye a un debate de plena actualidad. Precedido de una minuciosa tarea de documentación, como revelan las notas a pie de página, y con un exhaustivo aparato bibliográfico, el estudio proporciona una información sumamente útil para situar en su debido contexto el significado económico y social del fracking, a la par que desvela sus claves jurídicas en el Derecho de los Estados Unidos, de la Unión Europea y de nuestro país.

II.- Tras el prólogo del profesor Tomás Quintana López, la obra comienza con una introducción en la que sintéticamente se expone el estado de la cuestión, a la que siguen seis capítulos, un anexo sobre los productos químicos que se utilizan en Estados Unidos y el índice de bibliografía y documentación básica.

El primer capítulo ("El gas como opción energética: historia y situación actual") expone los aspectos históricos del uso de la energía y del gas, prestando especial atención a lo acontecido en España, país en el que tardíamente se introduce el gas natural. Desde el uso anecdótico del gas de carbón en agosto de 1792 hasta el momento actual, en el que "el peso del gas natural en el mix de energía representa el 20\%", el autor repasa los principales hitos del empleo del gas, del marco normativo y de la organización administrativa del sector.

El segundo capítulo ["Gas no convencional y fractura hidráulica (fracking): definiciones"] aborda los conceptos técnicos imprescindibles para la comprensión de las técnicas de exploración y explotación del gas no convencional, en particular el fracking. Además de todo ello y al hilo de la explicación de los métodos utilizados, se da cuenta de la trayectoria seguida en los Estados Unidos y de las claves del éxito del fracking en esta nación, cifradas principalmente en acuerdos con empresas privadas para impulsar el desarrollo de las tecnologías precisas, la política fiscal favorable y un marco normativo propicio; también se subraya el impacto del éxito sobre los precios del gas natural, la generación de empleo y riqueza y la situación de autoabastecimiento del país. Igualmente se reseñan las perspectivas de explotación en la Unión Europea y se ofrece una prospectiva sobre el futuro del mercado de la energía.

El tercer capítulo ["La incidencia ambiental del uso de la fractura hidráulica (fracking) en la exploración y explotación de gas no convencional"] se inicia con un recordatorio de las ventajas económicas y de las repercusiones sociales del gas no 
convencional, con referencias concretas al estado de la cuestión en Estados Unidos, la Unión Europea y España. Esta reseña es el punto de partida para el análisis de las implicaciones ambientales del fracking, que se concretan en el consumo de agua, el riesgo de contaminación de las aguas superficiales y subterráneas, la sismicidad inducida, las emisiones atmosféricas (entre ellas las de gases de efecto invernadero) y la incidencia en el suelo y en el paisaje. Por lo que respecta al consumo del agua, el autor destaca que en Estados Unidos es "muy inferior al derivado de la generación eléctrica en centrales térmicas, para el suministro municipal o para el regadío agrícola”. En cuanto al riesgo de contaminación de las aguas, llama la atención acerca de la importancia que reviste la elección de zonas en las que no existan materiales permeables, la integridad y estanqueidad de los pozos y el tratamiento de las aguas residuales de retorno; al hilo de esta cuestión, recuerda que los aditivos químicos han de ser los previstos en la normativa y de público conocimiento; también subraya que la Agencia de Protección Ambiental estadounidense ha concluido que no existe un impacto generalizado en el agua potable, al margen de algunos casos puntuales ocurridos en el ejercicio de actividades rutinarias y accidentes. Sobre la sismicidad inducida, informa que es baja o muy baja, según se desprende de distintos estudios que también recogen las medidas preventivas que se han de adoptar y la necesidad de establecer sistemas de detección temprana y vigilancia. De las emisiones atmosféricas, destaca que no parecen muy posibles las fugas incontroladas de gas metano a la superficie, que los sistemas de control de fugas son mucho más exhaustivos que los implantados en otras actividades y que las emisiones "si existen, no son superiores a las derivadas de gas convencional, y en todo caso, ambas son más limpias que otros combustibles fósiles". Sobre la incidencia en el suelo y en el paisaje, muy considerable e inevitable, apunta que las innovaciones que suponen las perforaciones horizontales de los pozos mitigan el impacto. La conclusión a la que llega el autor es clara: el fracking no supone realmente un peligro ni un riesgo mayor que otras actividades industriales, siempre que se respete la normativa reguladora y las buenas prácticas aplicables, de las que proporciona algunos ejemplos.

En el cuarto capítulo ("Aproximación al Derecho estadounidense aplicable al gas no convencional y al fracking"), el autor explica que las competencias en la materia y sobre protección del medio ambiente corresponde a los Estados federados, que las han ejercido de modo desigual. Así, algunos de ellos han aprobado normas prohibitivas; otros, normativas que permiten la actividad, pero con un acusado carácter restrictivo; y la mayoría ha regulado "un conjunto menor de los problemas de obtención de gas y petróleo”. En particular, llama la atención acerca de la también desigual consideración que, en términos de transparencia, merece la publicidad de la composición de los fluidos que se inyectan, que para algunos Estados es información accesible mientras que otros consideran que forma parte del secreto comercial. Se- 
guidamente, se centra en la legislación federal aplicable a la actividad de fracking, en particular la legislación ambiental; en concreto, expone en qué medida es aplicable la Ley de Agua Potable Segura de 1974, la Ley de Conservación y Recuperación de Residuos de 1976 (tras la exclusión producida por la Ley de Eliminación de Residuos Sólidos de 1980), la Ley de Aire Limpio de 1970, la Ley de Especies en Peligro de 1973, la Ley del Tratado de Aves migratorias de 1918, la Ley de Planificación de Emergencias y Derecho a Saber, la Ley de Seguridad y Salud Ocupacional y la Ley de Responsabilidad, Compensación y Recuperación Ambiental; asimismo da cuenta de la exclusión de la Ley sobre el Control del Agua de 1948 y de la Ley de Política Ambiental Nacional de 1969. También refiere la reglamentación basada en el control que corresponde al Gobierno federal en cuanto propietario de territorios, por cierto muy amplios, en los que se desarrolla el fracking. El capítulo concluye con una llamada de atención sobre la incidencia del régimen del derecho de propiedad, toda vez que el propietario lo es tanto del suelo como del subsuelo y de sus recursos; y con una advertencia acerca de los cambios que se pueden producir con la nueva Administración Trump.

El quinto capítulo ["Régimen de la Unión Europea aplicable a la exploración y producción de gas no convencional mediante fracturación hidráulica (fracking)"] comienza con la exposición de la situación del gas no convencional en la Unión Europea, poniéndose de manifiesto la dependencia energética de la Unión Europea y de algunos de sus Estados miembros, así como otros puntos débiles. A continuación se trata la evolución y la regulación actual de la política de energía de la Unión Europea, llamando la atención acerca de la novedad que supone el Título XXI y el artículo 194 del Tratado de Funcionamiento de la Unión Europea y exponiendo la serie de documentos y pronunciamientos que se han sucedido relativos a la energía y otros aspectos relacionados, con particular atención a las ocasiones en que se ha aludido a los recursos no convencionales y a los documentos específicos sobre la materia, proporcionándose una información muy completa. Destaca el tratamiento que efectúa de la Recomendación de la Comisión 2014/70/UE, de 22 de enero, relativa a unos principios mínimos para la exploración y producción de hidrocarburos, como el gas de esquito, utilizando la fracturación hidráulica, que caracteriza como "un texto avanzado en la materia, al incluir todo lo necesario para que las operaciones de extracción de hidrocarburos no convencionales se realicen con total seguridad y sin riesgos para el medio ambiente ni para la salud humana". Por último, ofrece una panorámica de la normativa europea aplicable, distinguiendo entre la relativa a las actividades extractivas, la normativa en materia de aguas, de sustancias químicas, de control de riesgos en accidentes graves en los que intervengan sustancias peligrosas, sobre la seguridad de las operaciones relativas al petróleo y al gas mar adentro y la normativa ambiental (las directivas de evaluación de planes y programas y de 
proyectos, así como las directivas de hábitats naturales y de conservación de las aves silvestres).

El sexto capítulo ["La regulación de la obtención de gas no convencional mediante fractura hidráulica ( fracking) en España”] se divide en cinco partes de desigual extensión. Tras una breve introducción en la que fundamentalmente se pone de manifiesto que en nuestro país no hay suficientes procesos de exploración y sondeos para determinar si existen yacimientos relevantes para considerar la extracción de recursos no convencionales, se aborda la distribución de competencias en la materia. El autor expone la doctrina jurisprudencial sobre los títulos competenciales del Estado, destacando que las Comunidades Autónomas no pueden prohibir "una determinada actividad o técnica en materia o sectores sobre los que carecen de competencias"; a continuación analiza las distintas sentencias del Tribunal Constitucional que han declarado la inconstitucionalidad de las normas autonómicas que han prohibido el fracking y expone el estado de la cuestión en relación con la Ley vasca 6/2015, de 30 de junio, dando cuenta asimismo de otras iniciativas autonómicas; seguidamente se ocupa de la jurisprudencia del Tribunal Supremo recaída al hilo de un intento de convocatoria municipal de una consulta popular y de distintos recursos contra el otorgamiento de permisos de investigación. En la segunda parte de este capítulo se reseñan los documentos estratégicos producidos en España sobre los hidrocarburos no convencionales y la fracturación hidráulica, verdaderamente escasos. En la tercera y en la cuarta parte analiza la legislación española aplicable a la materia; la tercera parte se centra en la legislación de hidrocarburos, dedicando especial atención a la incidencia de la Ley 8/2015, de reforma de la Ley del Sector de Hidrocarburos; la cuarta parte, en cambio, se dedica a la Ley 21/2013, de Evaluación Ambiental, de la que destaca su carácter avanzado respecto de la Directiva 2011/92/UE, puesto que somete a evaluación ambiental las operaciones de exploración y de extracción de gas no convencional mediante fractura hidráulica; también en esta cuarta parte se menciona la aplicación de la legislación de aguas, de conservación de la naturaleza, en su caso de la legislación de minas, de la legislación de residuos, de la normativa sobre seguridad industrial, sobre sustancias químicas y peligrosas, sobre responsabilidad medioambiental y la relativa a operaciones extractivas en el mar. En la quinta parte, finalmente, se reseñan las propuestas prohibitivas que se han presentado en el Congreso de los Diputados, llamando la atención acerca de nuestra dependencia energética y el hecho de que no se avanza en la realización de sondeos y evaluación de posibles recursos no convencionales; el autor recuerda el éxito del fracking en otros países y cómo las innovaciones en el sector se orientan a una mejor protección del medio ambiente, concluyendo sobre la necesidad de realizar los referidos sondeos exploratorios, que incluso pueden revelar la inutilidad del actual debate sobre el fracking. 
III.- La monografía que se recensiona contiene un exhaustivo análisis jurídico de la materia que constituye su objeto, en un momento especialmente oportuno ante el debate abierto sobre el fracking. Por esta razón merece un juicio muy positivo y se recomienda vivamente su lectura. Pero, además, la obra presenta un valor añadido que la hace especialmente útil, ya que aporta el conocimiento necesario para poder comprender la realidad subyacente.

La creciente complejidad de los fenómenos que deben disciplinar las normas supone uno de los mayores retos a los que debe enfrentarse el jurista y en general el aplicador del Derecho. Cada vez con mayor frecuencia resulta difícil interpretar la ley y no es sencillo tampoco valorar su oportunidad sin unos conocimientos previos sobre la materia que regula. Así sucede de manera especial en el caso de la normativa ambiental y de sectores de actividad como el que es objeto del libro del profesor Fernández de Gatta. De ahí que uno de sus aciertos sea el enfoque que adopta en su estudio, que brinda una magnífica oportunidad al lector para alcanzar un cabal conocimiento de las implicaciones técnicas, económicas y sociales de una actividad discutida en cuanto a sus repercusiones ambientales y en términos de seguridad. Así lo destaca el profesor Quintana López en su prólogo, del que subrayo su apreciación, que plenamente comparto, de que estamos ante "un trabajo documentado hasta la extenuación y rico en juicios sustentados en argumentos bien fundados".

María del Carmen Núñez Lozano

Catedrática de Derecho Administrativo

Gentro de Investigación en Patrimonio Histórico, Cultural y Natural

Universidad de Huelva 